\title{
Educação geográfica para a formação cidadãa
}

\author{
Helena Copetti Callai²
}

\begin{abstract}
RESUMEN
La formación para la ciudadanía es un tema significativo en la educación básica, la reflexión sobre la contribución de la educación geográfica sustenta la hipótesis de este análisis centrado en la argumentación de que a través de la geografía existen caminos posibles para a formación ciudadana. Para comprender como es desarrollada la tarea de educar para la ciudadanía a través de los contenidos de la geografía escolar, es abordado el lugar como concepto y espacio de vida de los estudiantes y el papel del libro didáctico en ese contexto. Las bases teóricas y metodológica critica hermenéutica sustentan la interpretación de los datos producidos en las entrevistas con profesores, y en el análisis de los libros didácticos. Se constata que la educación geográfica es entendida como la posibilidad de estudiar los contenidos de la geografía creando la oportunidad de una formación ciudadana. Pero en las acciones prácticas de la escuela y en el contenido de los libros didácticos el aprendizaje del alumno se restringe a la mera repetición del contenido.
\end{abstract}

Palabras clave: Geografía, ciudadanía, libro didáctico, lugar.

\begin{abstract}
The constitution of citizenship is a significant subject in basic education, and the reflection about the contribution of geographycal education sustains the hypothesis of this analysis focused on the argumentation that through geography there are possible paths towards the citizen formation. To understand the development of the process of education towards citizenship through geography in schools, the place is defined as concept of space of living for the students, and the textbooks have central role in it. The theoretical and methodological basis, as well as the hermeneutical critique, sustain the interpretation of data produced from interviews with teachers and the analysis of textbooks. It is verified that geographycal education is understood as the possibility opportunizing the constitution of the citizen through studying geographic matter. However, in the practical actions in schools and the matter of the textbooks, the learning process is reduced to simple repetition of written knowledge.
\end{abstract}

Keywords: Geography, citizenship, textbook, place.

Projeto de pesquisa financiado pelo CNPq como Bolsista de produtividade em pesquisa - PQ/CNPq- Nível 1D com o título: "Educação geográfica: escala de análise como ferramenta intelectual para educação cidadã". O projeto de pesquisa foi iniciado em 01/03/2015 e encerra em 28/02/2019. Artículo recibido el 13 de septiembre de 2017, aceptado el 26 de marzo de 2018 y corregido el 5 de junio de 2018.

Universidade Regional do Noroeste do Estado do Rio Grande do Sul (Brasil). E-mail: copetti.callai@gmail.com 
A educação geográfica tem como meta a abordagem dos conteúdos da geografia nos processos do ensino e da aprendizagem oportunizando ao aluno acesso ao conhecimento de modo que o torne significativo para que assim possa elaborar o seu próprio pensamento e produzir o seu saber. Este processo tem referência ao conhecimento científico realizado pela produção da ciência geográfica e, na contrapartida com o conhecimento do cotidiano, pode ser elaborado o conhecimento geográfico disciplinar, que é o trabalhado na escola. E neste âmbito se insere a questão da cidadania que tem assumido relevância nas discussões sobre a escola e educação. A educação geográfica para a formação cidadã, aqui abordada na proposição de educação e cidadania no estudo da geografia, objetiva fazer a reflexão a respeito dos subsídios ao ensino da geografia escolar na educação básica brasileira para a construção da cidadania.

Educação e cidadania têm sido uma proposição de longa data expressa nos documentos das políticas públicas no Brasil. Ganha realce, no entanto, com o processo de abertura política no Brasil, pós-ditadura de 1964, e está indicada em documentos importantes tais como: Constituição da República Federativa do Brasil - 1988, que foi denominada Constituição Cidadã; Lei de Diretrizes e Bases da Educação Nacional - LDB/1996; Parâmetros Curriculares Nacionais- PCNs/1997; Diretrizes Curriculares Nacionais da Educação Básica - DCNs 2013; Programa Nacional do Livro Didático - PNLD. No entanto, deve-se referir que mesmo no período da ditadura a questão aparecia nas orientações curriculares, (e nos livros didáticos) inclusive com a inclusão das disciplinas de Educação Moral e Cívica - EMOCl e Organização Social e Política Brasileira - OSPB na Educação Básica e, no Ensino Superior com a disciplina denominada Estudo de Problemas Brasileiros - EPB. Todas com a indicação de abordar a cidadania no âmbito da educação escolar. Diante disso, é fundamental compreender o significado atribuído ao conceito de cidadania em cada tempo, pois que o conceito e entendimento de cidadania numa época de ditadura não será o mesmo em um período democrático.

A reflexão apresentada versa sobre essas questões considerando os autores/pesquisadores da geografia que abordam o tema de modo direto (na geografia escolarizada), ou também indiretamente nas pesquisas realizadas na ciência geográfica. A estrutura deste artigo considera, portanto, a análise dos conceitos de cidadania e de lugar, tendo como parâmetro a proposição de Milton Santos quando diz que "cada lugar é, ao mesmo tempo, objeto de uma razão global e de uma razão local, convivendo dialeticamente" (Santos, 1996: 273). Diante disso, fazendo um recorte e, buscando o tratamento dos objetivos da geografia escolar, a temática deste artigo se inscreve no ensino de geografia abordando as possibilidades de contribuir para a formação da cidadania. Entende-se que educação e cidadania têm que proporcionar a bagagem conceitual e os recursos necessários para compreender a natureza dos problemas e buscar soluções fazendo frente ao incerto, ao desconcertante inclusive. Assim, o desafio é como educar para a participação cidadãos ativos diante do compromisso social e de trabalho solidário.

Neste sentido, o artigo, que é parte de uma investigação mais ampla, se caracteriza por compreender como é desenvolvida a tarefa de educar para a cidadania através dos conteúdos da geografia escolar. Para tanto, o estudo do lugar como conceito e como espaço de vida dos estudantes é considerado na pesquisa realizada, assim como o papel do livro didático nesse contexto. Além de estudo bibliográfico, a partir de autores da ciência geográfica e dos que se dedicam a analisar os aspectos pedagógicos da geografia escolar, foram ouvidos professores para caracterizar, a partir do campo empírico, os entendimentos a respeito da questão considerando a dimensão teórica que oportuniza as bases para abordagem dos conteúdos e dos processos ligados à 
dimensão pedagógica dos conteúdos. É interessante observar que, nas intenções, sempre se faz presente um discurso que na pratica raramente é efetivado o que pode ser constatado pela parte empírica. As bases teóricas da geografia nos permitem estabelecer os conceitos e o modo como trabalhar a geografia escolar e os resultados produzidos no campo empírico atestam as preocupações com o sentido da educação geográfica.

A bibliografia existente a respeito da questão é extensa, seja como artigos que apresentam ensaios sobre a problemática e as suas perspectivas teóricas, seja como resultado de estudos acadêmicos e também através de relatos de experiência. Seleciono os mais significativos para a reflexão atual. A obra "Novi Cíves- Cittadini dall infanzia in poi" (Borghi et al., 2015), é referência importante para este artigo, pois apresenta resultados de uma linha de pesquisa coordenada pela Universidade de Sevilla-Espanha e desenvolvida entre janeiro de 2012 e 31 de dezembro de 2014, ${ }^{3}$ envolvendo pesquisadores da Espanha, Itália, Portugal, Brasil e Colômbia. E, além dos resultados específicos dessa pesquisas, a obra citada incorpora trabalhos apresentados em Bolonha na "Festa Internazionale della Storia". ${ }^{4}$ Nessa obra organizada em três partes são apresentadas reflexões sobre: 1. Cidadania e educação para a cidadania: fundamentos e reflexões; 2 . O ensino da participação cidadã com ensaios resultantes das várias pesquisas realizadas pelos membros do grupo; 3. Experiências e projetos de educação para a participação cidadã. Por serem resultados de intenso trabalho no decorrer de três anos as análises apresentadas foram discutidas e tensionadas durante o período da pesquisa, da qual fiz parte com mais outros três pesquisadores brasileiros ${ }^{5}$. Destes estudos, no contexto do referido grupo brasileiro, resultaram dois artigos que abordaram a cidadania no contexto brasileiro, através de um ensaio (Lastória et al., 2015: 43-52) e de análise de experiências (Lastória et al., 2015: 191-199) E, na mesma perspectiva, no artigo "A educação para a cidadania e a pesquisa" (Callai \& García Pérez, 2016: 22-42) é abordada a formação para a educação cidadã a partir da análise de experiências de dois lugares: Sevilla- Espanha e ljui-RS- Brasil.

\section{Importância de trabalhar com conceitos}

Como base para interpretação da educação geográfica e formação para a cidadania, considera-se o trabalho escolar na construção de conceitos, como aspecto essencial no desenvolvimento da aprendizagem. Os conceitos permitem fazer generalizações com o desenvolvimento do pensamento abstrato, o que permite ver o mundo não apenas como um conjunto de coisas, mas fazendo teorizações abstraindo dos fragmentos (que são os conteúdos) através de operações intelectuais. Esse processo requer que seja possibilitado ao aluno as condições para fazer a teorização, o que pode ser realizado através do confronto dos conceitos cotidianos e dos conceitos científicos, produzindo os processos de abstração de modo que ao fazer as generalizações ele tenha ferramentas intelectuais para aprender a geografia.

Coordenado por Francisco Florentino García Pérez - Universidade de Sevilla- Espanha Proyecto I+D+i, com referência EDU2011-23213, denominado "Estratégias de formación del professorado para educar en la participación ciudadana" financiado por el Ministério de Ciência y Tecnologia del Gobierno de España y com Fondos FEDER.

"XI Festa Internazionale della Storia" realizada em outubro de 2014 na Sala Stabat Mater, da Biblioteca de I'Archiginnasio, em Bolonha-Itália. Andrea Coelho Lastória-USP- Ribeirão Preto; Helena Copetti Callai - UNIJUI- RS; Lana de Souza Cavalcanti e Vanilton Camilo de Souza - UFGGoiás. 
Os temas da geografia escolar têm sido apresentados na escola, através de recortes de espaços fragmentados que levam a constituir a ideia de fenômenos isolados. E, por isso, as aulas de geografia compõem um rol de assuntos que têm as explicações artificializadas e naturalizadas como se o espaço geográfico não tivesse a dimensão do trabalho humano, que é historicamente produzido e está localizado nos lugares específicos. Essa situação remete a um ensino pragmático em que os conteúdos devem ser memorizados, o que dificulta a elaboração da reflexão de modo a dar significado ao aprendido, ou melhor, àquilo que é transmitido nas aulas. O desafio é, então, como superar a fragmentação dos conteúdos de modo a não abandoná-los, mas para que sirvam de possibilidade para a construção dos conceitos no contexto da aprendizagem. A escola é onde os jovens e crianças vão para aprender aquilo que é produto da história da humanidade, que é o conhecimento científico. E, neste sentido, a escola é onde "o mundo é tratado como um objeto do pensamento", (Young, 2011: 615), portanto, os conteúdos curriculares são o resultado da produção cientifica que deve ser transmitida aos estudantes, e, "As disciplinas reúnem objetos de pensamento como conjuntos de conceitos sistematicamente relacionados", (Young, 2011: 615). O papel da escola é oferecer aos alunos as condições para fazer o exercício da abstração com o intuito a terem o acesso ao conhecimento e com a finalidade de desenvolvimento intelectual, o que é fundamental para a vida e assim se constituírem sujeitos capazes de enfrentar as demandas profissionais e sociais. E, seguindo essa argumentação, os conceitos são a base de sustentação do desenvolvimento intelectual, pois, "os conceitos são sempre sobre alguma coisa. Eles implicam alguns conteúdos e não outros. O conteúdo, portanto, é importante não como fatos a ser memorizados, [...] mas porque sem eles os estudantes não podem adquirir conceitos e, portanto, não desenvolverão sua compreensão e não progredirão em seu aprendizado", (Young, 2011: 614). Dentre os conceitos que interessa abordar está o de lugar que considero um dos mais significativos para trabalhar a geografia tendo presente a ideia do mundo atual onde o global e o local se interconectam numa perspectiva dialética para produzir os lugares.

\section{Sobre a cidadania}

Vários autores abordam a temática com base no conceito em si e incluindo as ações do cotidiano, perspectiva que reforça a ideia de que esperamos que a aula de geografia, através dos conteúdos que lhe são específicos, possa instrumentalizar o aluno a fazer a teorização das questões da sua própria vida no lugar em que a vive. Neste processo, espera-se que o aluno se capacite a construir os conceitos que levam ao conhecimento. Considero que cidadania "enfaixa uma série de direitos, deveres e atitudes relativos ao cidadão, aquele indivíduo que estabeleceu um contrato com seus iguais para a utilização de serviços em troca de pagamento (taxas e impostos) e de sua participação, ativa ou passiva, na administração comum", (Pinsky, 1999: 18). A cidadania implica em se reconhecer com identidade e pertencimento no mundo comum e "que implique a manifestação de uma consciência de pertinência e responsabilidade coletiva" (Pinsky, 1999: 18).

Milton Santos em várias obras $(1988 ; 1994 ; 1996 ; 2000)$ considera fundamental para a vida cidadã e dignidade dos sujeitos, e como tal a eficácia da aprendizagem, se tivermos acesso aos bens produzidos pela humanidade. Entre estes bens está um muito valioso que é o conhecimento que a humanidade produziu ao longo de sua história e que deve ser transmitido na escola de modo que o aluno se aproprie e construa a sua aprendizagem. Para isso, é adequado ter presente o conjunto dos processos que no mundo atual massifica e coisifica transformando tudo em 
mercadorias e considerando tudo igual. E, neste entendimento, na obra de Santos constata-se a seguinte observação,

“...para ter eficácia o processo de aprendizagem deve em primeiro lugar, partir da consciência da época em que vivemos. Isso significa saber como o mundo é e como ele se define e funciona, de modo a reconhecer o lugar de cada País no conjunto do planeta e o de cada pessoa no conjunto da sociedade humana. É deste modo que se podem formar cidadãos conscientes, capazes de atuar no presente e de ajudar a construir o futuro" (Santos, 1994: 121).

É importante reiterar que na escola o fundamental é oportunizar acesso ao conhecimento que é produzido cientificamente, o qual toda a criança e o jovem têm direito. Este processo significa oportunizar aos alunos as ferramentas intelectuais para agir no próprio momento da vida em que estão, isto é, ser sujeito que vive como tal com direitos e deveres no presente, pois como diz o autor antes referido, ajuda assim a construir o futuro.

\section{O estudo do lugar e a cidadania}

O conceito de lugar, como qualquer outro conceito, precisa ser considerado no contexto histórico em que é abordado, fluindo deste modo o seu delineamento. Aliás, esse é um conceito que tem sido proposto como elemento curricular nos documentos de políticas de educação no Brasil ao longo do tempo, o que se pode constatar pelo que está apresentado já numa obra de 1934 "Programas e guias de Ensino do Departamento de Educação do Distrito Federal" em que diz que, trabalhar com o conceito de lugar como um dos (conceitos) que permitem e que oportunizam aprofundar a noção de espaço geográfico, básico nesta disciplina, é fazer aquilo que historicamente se propõem, em determinados períodos como a possibilidade de mostrar às crianças o exótico e despertar neles a imaginação e criatividade. Tradicionalmente nos anos iniciais da escolaridade, com base em teorias que referem que a criança aprende através de estágios que vão se sucedendo linearmente ao longo do tempo (perspectiva Piagetiana dentre outras), o lugar tem sido objeto de estudo para que a criança desenvolva o conhecimento sobre ele abordando as questões que se constituem como elementos significativos para a vida da criança.

Em outras perspectivas teóricas, o conceito de lugar é considerado como a estratégia de estudar territórios alternativos onde acontecem fenômenos que fazem a diferença num contexto de globalização, (Haesbaert, 2002). É abordado também como a possibilidade de estudar a organização da população oportunizando - Ihes a capacidade de constituição de sua identidade e pertencimento ao lugar, tendo em vista a "Força do lugar". Esta proposição é a que adoto a partir de Milton Santos e que considero o caminho para aprender aquilo que a geografia pode oportunizar para que cada pessoa se reconheça como sujeito cidadão e que perceba, valorize e tenha as condições de construir e preservar a sua identidade e seu pertencimento. Nesse contexto, "el Lugar se entiende, no solo como referencia al objeto de la geografía, sino que además se entiende como una posibilidad metodológico-analítica para comprenderlo y explicarlo, al mismo tiempo, como una posibilidad de recomponer la interrelación entre los seres humanos y el medio". (Garrido, 2009:15). O lugar assim entendido é um conceito que carrega em si o movimento da vida. 
Vivemos num mundo que tem em suas histórias as culturas, os modos de viver, de conviver, os processos de produzir bens e de produzir as próprias vidas. Neste sentido, é importante reconhecer que somos educados por tudo que nos rodeia, seja material/concreto ou imaterial, a natureza, os convívios, as linguagens e a palavra. Somos educados pelo lugar que habitamos, onde moramos, pelos lugares próximos e, também, pelos lugares mais distantes que têm interligação com as nossas vidas. Esta interpretação traz consigo a perspectiva da escala de análise que sustenta que estudar o lugar não é o mesmo que estudar o local. Este tem os contornos que o delimitam e que fazem com que o espaço absoluto, restrito aos limites que lhe são postos, impeçam de perceber que o mundo é mais amplo e complexo. Por isso, importa considerar o lugar como um conceito e como um lugar de vida e as estratégias pedagógicas são o elo que podem oportunizar o exercício da reflexão.

$E$, uma questão que, particularmente, interessa refletir é a dimensão pedagógica do fazer escolar, cabendo ao professor assumir estratégias para tornar acessível o conhecimento. Essa condição exige que se considere quem são os alunos, qual o contexto em que vivem, o nível do conhecimento do professor a respeito da disciplina com que trabalha e inclusive os conhecimentos do cotidiano que o alunos possuem. O desafio é como fazer a interação entre o conhecimento científico e a experiência do aluno de modo a que a escola cumpra seu papel que é oportunizar o conhecimento para o desenvolvimento intelectual de seus alunos. É oportuno considerar que no lugar onde os alunos vivem, eles tem uma convivência mais direta com as pessoas que ali habitam, seja cidadãos comuns, seja as autoridades. Desenvolve-se uma experiência de vida com este lugar, elaborando um conhecimento que é do cotidiano, e que pode estar pleno de preconceitos por serem do senso comum, ponto fulcral onde reside o trabalho pedagógico do professor que tem o conhecimento disciplinar. O desafio é ir além do senso comum.

Trabalhar os conteúdos da geografia ao estudar o lugar, além deste, outros conceitos: espaço, território, paisagem, que são próprios da geografia, devem ser envolvidos. Para fortalecer estes conceitos é necessário o acesso aos conhecimentos, aos objetos que permitem pensar teoricamente e compreender intelectualmente o referido conteúdo. No lugar, conceito e local de vida dos estudantes, as paisagens tornam visíveis o espaço construído e o aluno pode compreender que faz parte daquele lugar, que pode participar das decisões na escola, nos lugares que percorre e com isso ter mais elementos para entender que o que acontece no lugar resulta de como os homens vivem, decidem, estabelecem as relações. Relações com o poder político, pois os representantes da população que atuam no executivo e no legislativo estão próximos; com o mundo da economia pela proximidade com as empresas onde as pessoas trabalham, etc. Essa proximidade permite que o aluno conheça pelo seu cotidiano aquilo que é vivido. O exercício da teorização fortalecido pela interpretação com a escala de análise encaminha ao entendimento das questões. Assim, pode perceber que nada é ao acaso, mas que o espaço construído reflete os resultados das relações entre os homens, das histórias que se materializam nas paisagens, das edificações e das memórias. Mas pode perceber também que o lugar não é isolado do resto do mundo e que muita coisa que ali acontece decorre de demandas e condições externas. Tendo este olhar para o lugar, pode-se ao estudá-lo buscar com que as aprendizagens resultem em consciência cidadã tendo a dimensão da construção da identidade e pertencimento. 


\section{A força do lugar e a escala de analise}

O conceito de lugar na vida das pessoas e na realização das atividades do cotidiano das suas vidas, reafirmo, precisa ser abordado e compreendido teoricamente para não ficar num simples empirismo que dificilmente pode contribuir com a aprendizagem e com a formação para a cidadania. Nesse sentido, um conceito que se sobressai neste contexto é o da "força do lugar", de Milton Santos, considerado em todas as suas obras e em especial no livro publicado em 1996. Contribui nessa abordagem também outras obras como o texto intitulado "Estudar o lugar para compreender o mundo" (Callai, 2010) e uma obra que reúne autores brasileiros e latino americanos denominada "La espessura del lugar", coordenada e organizada por Marcelo Garrido (2009). A partir disso, é significativo e considerado adequado o estudo da questão da multiescalaridade. Esses conceitos são importantes para entender que cada escola, cada grupo da comunidade escolar e inclusive o bairro e o município em que se situam são importantes para compreender a realidade do lugar. Esta questão diz respeito a considerar o espaço como produção dos homens em sua vida comum, pois as histórias de vida ficam registradas na materialização das mesmas no espaço. A força do lugar decorre da capacidade das pessoas que ali vivem fazer a construção das suas próprias vidas no jogo de forças entre o local e o global, entre as demandas externas e os interesses do lugar em que vivem. Demandas essas que são das pessoas e dos grupos e, que se refletem no lugar por meio da materialização das relações sociais.

Reforço neste sentido o cuidado e a atenção com a escala de análise, pois o lugar (ou os lugares) não pode ser estudado isoladamente como se tudo que existe neles se explicasse por si mesmo, sem interferências externas. $O$ jogo entre o conhecimento do aluno e o que ele pode conhecer verificando/estudando o lugar em que vive, não pode se esgotar em si mesmo. Ficar-se-ia assim numa geografia apenas descritiva - que observa e descreve lugares. $O$ desafio que se apresenta é como fazer com que estes conhecimentos da vida, que se constituem na/da experiência de viver no lugar possam ser contextualizados realizando a abstração e teorização de modo a pensar o lugar como um conceito da geografia, como o conceito de uma cidade, de uma região. Nesta perspectiva, importa muito, portanto, que o aluno possa compreender o lugar em que ele vive situado num contexto mais amplo e com demandas que não necessariamente são aquelas que interessam as pessoas do lugar, apenas. Ali está um espaço que tem história e tem edificações que indicam os acontecimentos, pois nos lugares se materializam as histórias dos homens e o objetivo é entender essas questões situando-as no mundo da vida, no entanto não simplesmente como experiências, mas também desenvolvendo o pensamento, tendo os instrumentos metodológicos para abstrair e intelectualmente construir o seu saber.

Como parte dessas ferramentas intelectuais está a escalaridade (a multiescalaridade ou a escala social de análise) que remete a que se perceba essas questões na dimensão dialética do espaço absoluto, relativo e relacional. $\mathrm{E}$, também, considerando na mesma perspectiva as escalas de local e global, precisam ser compreendidas numa dimensão dialética que anula o caminho simplificado linear, mas considera-o na sua complexidade. Haesbaert, (2002), num texto em que perguntado sobre o que diria aos jovens, acentua que a sensibilidade e o emocional não podem ser esquecidos, mas que devemos colocar lado a lado o sentimento e razão, pois que: "Esta separação entre razão e sensibilidade foi ou é a nossa mais infeliz dicotomia" (Haesbaert, 2002: 170). E considera, portanto, que o estudo do lugar "reavaliado à luz dos processos contemporâneos, especialmente os de globalização, com certeza são um vasto campo a ser explorado pelo geó- 
grafo que ainda acredita nas possibilidades efetivamente integradoras e multidimensionais da geografia (Haesbaert, 2002: 171).

Estabeleço então a ligação com o título do livro de Milton Santos "A Natureza do espaço- técnica e tempo - emoção e razão". A vida não é fria e não pode ser vivida simplesmente pela razão, a emoção faz complexificar o olhar e entender o mundo e as coisas da vida de modo mais humano, talvez. Neste livro aqui referindo em especial a $4^{a}$ parte que tem por título "A força do lugar" permite que seja pensada uma geografia com marcas da vida vivida no mundo comum. Quando diz que "o choque entre cultura objetiva e cultura subjetiva torna-se um instrumento da produção de uma nova consciência" (Santos, 1996: 261) faz pensar que num mundo onde a tecnologia impera, os interesses globais se manifestam em todos os aspectos e a construção da resistência pode ser opção. A vida está submetida ao jogo de forças externo a ela, e a valorização do sentimento, da emoção pode ter algum papel significativo na construção do mundo humano, pois "a globalização faz também redescobrir a corporeidade. O mundo da fluidez, a vertigem da velocidade, a frequência dos deslocamentos e a banalidade do movimento e das alusões a lugares e a coisas distantes, revelam em contraste, no ser humano, o corpo como uma certeza materialmente sensível, diante de um universo difícil de apreender" (Santos, 1996: 251). Considerar os sujeitos como tal e tendo a partir da escola o acesso ao conhecimento pode-se produzir condições ao exercício da cidadania. A educação geográfica se constitui nesse contexto em uma rica oportunidade de oferecer as ferramentas intelectuais aos alunos para analisar, interpretar e compreender o mundo.

A aprendizagem da geografia se coloca na perspectiva de pensar uma disciplina e um ensino que tenha a ver com a vida, e por isso a nossa preocupação constante com o lugar. Lugar como conceito da geografia e como conteúdo a ser trabalhado nas pesquisas e no ensino como uma possibilidade de entender o mundo em que vivemos, considerando a escala de análise geográfica que nos permite estabelecer a relação entre o global e o local sendo o lugar considerado numa "perspectiva en donde se reconoce como prioritário el reconocimiento de las relaciones entre medio y circunstancias del ser, que se vincula com la proximidade, la cotidianidad, la filiación, la pertenencia, el arraigo y la identidade" (Garrido, 2009: 15).

\section{Conceito de espaço}

Para refletir sobre a educação geográfica outro aspecto teórico metodológico se destaca, pois, para esta caracterização do lugar são tomados como referenciais os conceitos que permitem fazer o entrelaçamento entre o local e o global. Portanto, os conceitos de lugar, de cotidiano e de cidadania devem ser considerados numa perspectiva de multiescalaridade e para abordá-los e tê-los como elementos de análise é fundamental considerar que eles se referem ao espaço e que este remete necessariamente ao lugar que é onde vivemos, onde fazemos o nosso trabalho, onde acontecem as nossas relações que podem ser observadas ao serem vivenciadas. Para tratar do conceito de espaço, tendo presente as reflexoes anteriores, há que se considerar as diversas dimensões da escala de análise - a multiescalaridade, que diz respeito aos diversos níveis da escala que retrata o espaço (espaço absoluto, espaço relativo e espaço relacional). Vários autores abordam essa questão: Santos (1988;1994; 1996; 2000), Harvey (2012) e Massey (2008).

O espaço absoluto é aquela dimensão que remete a um lugar fixo, onde estão as coisas, que têm limites, que definem qual a área ocupada e que têm as características específicas inter- 
nas que podem mostrar o quadro, a feição de como é este lugar. Nas palavras de Harvey seria como ter "un muro alrededor de esto, generando una especie de cárcel y no podrian salir". (Harvey, 2012: 14). Esta dimensão do espaço tem sido de modo recorrente tema de geografia, ao estudar cada nação, cada país, cada região, cada cidade/município, bairro como se fossem únicas com suas características internas. Ao fazer isso a geografia remete ao entendimento que o lugar existe por si só e que a população que ali vive depende do que acontece ou do que pode ser feito ali dentro daquelas fronteiras. No caso de considerarmos a educação para a formação cidadã restringe ao que se poderia chamar de destinos ou num termo mais geográfico de determinismos.

O espaço relativo é aquele em que interessa a relação das pessoas seja entre si, seja entre as coisas e entre os grupos e dentro destes. É o espaço do movimento, não interessa apenas a dimensão absoluta mas a dimensão relativa e é fundamental considerar a que é relativo. São os movimentos das pessoas, dos povos, mas também das ideias. E no mundo atual este movimento é impactante de modo que superam-se as dimensões de espaço absoluto em si mesmo e os jovens têm contatos com o mundo exterior por vezes de modo mais intenso do que no seu grupo imediato. Por exemplo, a internet, que faz com que "las ideas se están moviendo dentro del espacio y del tiempo de una manera muy distinta a como era hace 300 años atrás" (Harvey, 2012: 14).

A outra dimensão do espaço que pode ser denominada de espaço relacional diz de abordar espaco-tempo e que se constitiu através de processos. A definição relacional se encontra aberta no sentido que se poderia fazer qualquer coisa que se queira com ela (Harvey, 2012: 16). Diz ele ainda que um sentimento relacional converte a memória em algo importante, em uma força política, (Harvey, 2012: 16). Importa ter a ideia de que esta dimensão de espaço envolve os aspectos materiais e imaterais. O intangível penetra nas nossas relações para conhecimento, decisão e inclusive subordinação ao que não se pode mudar.

Resta referir a respeito dessas três definições de espaço, que "tenemos que mirar en forma dialéctica entre todas ellas" (Harvey, 2012: 19), pois que o espaço absoluto é o ponto onde se concretrizam/materializam as coisas que são vividas e como tal ele é a dimensão visível dos acontecimentos. Mas não se explica sozinho e nem se pode encontrar nele todas as explicações, "porque lo que construyas ahí será una espresión simbolica del significado de aquel lugar donde funciona una economía global y también el simbolismo del poder" (Harvey, 2012: 19). O espaço construído socialmente é resultado das relações entre os homens que nele vivem e destes com a natureza e passa a ser um território apropriado que expressa em si por meio das rugosidades (Santos, 1988; 1994; 1996). A história das vidas de quem ali vive e também daqueles que viveram e deixaram as suas marcas. Para estudar e compreender o mundo "o espaço tem um papel privilegiado uma vez que ele cristaliza os momentos anteriores e é o lugar de encontro entre esse passado e o futuro, mediante as relações sociais do presente que nele se cristalizam" (Santos, 1994: 122). Esta é a perspectiva de espaço considerada que permite encaminhar a discussão da educação para a formação cidadã.

Enfim, compreender como é o mundo e como ele se apresenta a cada um de nós e aos grupos em que nos inserimos, exige que se considerem as escalas de análise que podem ser a chave que indica e leve à compreensão de que o que acontece num determinado lugar decorre de questões mais amplas e significativas no contexto da realidade brasileira e do mundo. E o professor neste contexto exerce o elo que lhe permite mediar o conhecimento produzido pela humanidade, os 
fenômenos que acontecem no mundo atualmente e o papel que cada um de nós pode ter neste contexto. Diante disso, pode-se argumentar que:

"a dimensão ética do trabalho do professor implica um ensino significativo, pleno de sentido e o caráter da escola como lugar específico para ensinar o que a humanidade produziu; tem o privilégio de fornecer os elementos necessários para a construção do conhecimento, para que o aluno construa o seu entendimento de mundo, para que seja sujeito de suas ações, enfim, para que exerça a sua cidadania" (Callai, 2013: 102).

\section{O olhar dos professores}

As orientações oficiais (a exemplo dos PCNs) indicam que o ensino de geografia deve primar por oferecer as condições de "conhecer e saber utilizar uma forma singular de pensar sobre a realidade: o conhecimento geográfico" (Brasil, 1997: 108). E, as aulas de geografia por meio desta orientação podem levar os alunos a fazer o que preconizamos como fundamental que é se apropriar das ferramentas intelectuais oferecidas pelas questões teóricas da disciplina e da sua ciência através de posturas que os facilitem a adquirir conhecimentos, operar com categorias, conceitos e procedimentos básicos deste campo do conhecimento.

Com este olhar que estabelece as bases de fazer a educação geográfica, realizo a observação, interpretação e análise dos dados e informações produzidas junto aos professores ${ }^{6}$. Esta produção empírica resulta do questionamento a um grupo de 20 professores da escola básica da região de ljuí - RS, que atuam nas instituições em que acontecem atividades semestrais de formação continuada a partir da universidade, considerando as demandas das próprias escolas. Foram convidados a participar professores que lecionam geografia e as entrevistas foram respondidas por escrito, após a conversa inicial onde foram apresentados os objetivos da investigação e apresentado o termo de livre concordância. Destaca-se que foram procurados 27 professores, dos quais 7 não aceitaram participar. A negação em responder pode demonstrar falta de solidariedade e desinteresse em colaboração num tema que não causa interesse imediato, além do entendimento pragmático de que é preciso vencer a lista de conteúdo, e por isso o mais importante é abordar os temas dos conteúdos curriculares. É o que se pode deduzir da falta de acolhimento em relação à pesquisa, mas é interessante referir que o fato de não ter respondido não foi motivo para o professor se excluir do debate que aconteceu a seguir.

Do ponto de vista pedagógico o debate é um momento de aprendizado, de crítica, de questionamentos e, portanto, interessa para pensar a questão da cidadania e da autonomia de pensamento. Muitas vezes o silenciado emerge nesses momentos de modo a desnudar a atitude do professor. É significativo que há aqueles que fizeram referência a que, no seu entendimento "Os direitos causam orgulho e brigamos por eles, e os deveres são obrigações impostas que muitas vezes desconhecemos como dever" e, também "Sempre encaramos deveres como um fustigante conjunto de obrigações". Estes professores de um modo geral fazem a crítica a posturas que existem na escola assumidas tanto por professores como direção, alunos e pais.

As entrevistas e os questionários foram aplicados no decorrer de 2016, a professores da escola básica, no contexto de pesquisa mais ampla, como bolsista de produtividade em pesquisa do CNPq. 
A seguir para abordar aquilo que pode ser denominado de o olhar do professor, é importante assinalar que dos dados produzidos, de acordo com o interesse da pesquisa (que é mais ampla), destaco neste artigo algumas questões que interessa aqui analisar diante da proposição de educação para a cidadania. No questionamento acerca de como realizam o estudo do lugar e se é possível criar condições para a formação cidadã através do estudo do lugar os depoimentos se caracterizam pelo indicado no Quadro $N^{\circ} 1$, a seguir.

Quadro No 1

Lugar e formação cidadã

\begin{tabular}{|c|c|}
\hline Como realiza o estudo do lugar & $\begin{array}{l}\text { Com o estudo do lugar pode-se criar condições } \\
\text { para formação cidadã? }\end{array}$ \\
\hline $\begin{array}{l}\text { Fazendo passeios e caminhadas ao entor- } \\
\text { no da escola. }\end{array}$ & $\begin{array}{l}\text { Sim, podem perceber que são importantes para } \\
\text { transformar o mundo e fazer o seu papel. }\end{array}$ \\
\hline Estudando pontos de cada lugar do Brasil. & $\begin{array}{l}\text { Sim, fazendo relações a partir do uso das tecnolo- } \\
\text { gias. Estudar o que existe e focar no lugar em que } \\
\text { vivem para comparações e ver o seu papel. }\end{array}$ \\
\hline $\begin{array}{l}\text { Observando o processo histórico os fatos } \\
\text { que geraram o ambiente, a economia a polí- } \\
\text { tica e a relação com o que existe atualmente. }\end{array}$ & $\begin{array}{l}\text { Com o debate dos processos e buscando a com- } \\
\text { preensão do que aconteceu e como é a realidade } \\
\text { atual. }\end{array}$ \\
\hline $\begin{array}{l}\text { Fazendo uso das novas tecnologias e da in- } \\
\text { ternet em especial. }\end{array}$ & $\begin{array}{l}\text { Com a apropriação dos conteúdos construindo } \\
\text { seus conhecimentos. }\end{array}$ \\
\hline $\begin{array}{l}\text { Sempre referenciando o que é estudado } \\
\text { com o que existe no lugar próximo para si- } \\
\text { tuar o aluno. }\end{array}$ & $\begin{array}{l}\text { Sim porque é o espaço onde o aluno atua, é o palco } \\
\text { das suas ações. }\end{array}$ \\
\hline $\begin{array}{l}\text { Estudando o local considerando a escala } \\
\text { ade análise- local, regional, nacional mun- } \\
\text { dial. }\end{array}$ & $\begin{array}{l}\text { Sim, pois o aluno pode fazer as abstrações e com- } \\
\text { preendendo que o mundo é globalizado e que tudo } \\
\text { interfere em todos os lugares. }\end{array}$ \\
\hline $\begin{array}{l}\text { Primeiro compreendendo os conceitos de } \\
\text { espaço e de tempo e depois visitar os lu- } \\
\text { gares, relacionar com o real, trabalhando } \\
\text { com mapas e com trabalho de campo. }\end{array}$ & $\begin{array}{l}\text { Ao estudar o lugar o aluno pode perceber que pode } \\
\text { ajudar a transformar. Conhecendo o lugar tem con- } \\
\text { dições de fazer mudar. E se pode contribuir no lu- } \\
\text { gar pode também em espaços mais distantes. }\end{array}$ \\
\hline $\begin{array}{l}\text { Com documentários, reportagens sobre } \\
\text { fatos do cotidiano. Sempre ligando o lugar } \\
\text { com o global. }\end{array}$ & $\begin{array}{l}\text { Sim, porque é agindo no local que vai refletir em } \\
\text { dimensões mais amplas. }\end{array}$ \\
\hline $\begin{array}{l}\text { Partindo do local e ir ampliando para es- } \\
\text { paços mais distantes e ai trabalhar os con- } \\
\text { ceitos. }\end{array}$ & $\begin{array}{l}\text { Sim, porque se meu aluno mora no lixão ele pode } \\
\text { se entender capaz de melhorar esse lugar com } \\
\text { ações locais e atenção do poder público. }\end{array}$ \\
\hline $\begin{array}{l}\text { Procurando fazer a ligação do local em que } \\
\text { se vive com o mundo porque apenas muda } \\
\text { a escala (questão ambiental, valores etc. }\end{array}$ & $\begin{array}{l}\text { É no lugar que temos maior poder de decisão de } \\
\text { interferir para melhorar a situação como um todo. }\end{array}$ \\
\hline $\begin{array}{l}\text { O lugar está ligado aos ambientes que nos } \\
\text { são familiares que fazem parte da nossa } \\
\text { vida, é o nosso lugar que nos dá uma iden- } \\
\text { tidade própria. }\end{array}$ & $\begin{array}{l}\text { Todo lugar está inserido num conjunto de lugares } \\
\text { formado por diferentes naturezas, mas unidos por } \\
\text { uma rede de relações. A partir dessa compreensão } \\
\text { o aluno pode conseguir se identificar no lugar e as- } \\
\text { sim agir de forma responsável como cidadão. }\end{array}$ \\
\hline
\end{tabular}




\begin{tabular}{|c|c|}
\hline $\begin{array}{l}\text { Com o estudo do lugar podemos contex- } \\
\text { tualizar as questões que envolvem a so- } \\
\text { ciedade e podemos perceber a diferença } \\
\text { cultural, em diferentes pontos da cidade. }\end{array}$ & $\begin{array}{l}\text { Sim, mas a pratica isso é muito complexa. A par- } \\
\text { tir da análise do problema do lugar, nós somos ca- } \\
\text { pazes de buscar os meios para direcionar o trabal- } \\
\text { ho na tentativa de obter a solução e esse trabalho é } \\
\text { formar, educar para a cidadania. }\end{array}$ \\
\hline $\begin{array}{l}\text { O estudo do lugar é feito a partir de um } \\
\text { conjunto de lugares, marcados por dife- } \\
\text { rentes relações políticas, econômicas, so- } \\
\text { ciais e ambientais, que se estabelecem em } \\
\text { diferente escalas: local, regional, nacional, } \\
\text { global. }\end{array}$ & $\begin{array}{l}\text { Sim, se pensarmos que no lugar que moramos, } \\
\text { trabalhamos nos divertimos e enfrentamos nossos } \\
\text { problemas. É por isso que não devemos poupar es- } \\
\text { forços para garantir o direito fundamental da cida- } \\
\text { dania. }\end{array}$ \\
\hline $\begin{array}{l}\text { Partindo da realidade do aluno, ao trabal- } \\
\text { har qualquer conteúdo sempre do local ao } \\
\text { global demonstrando que o lugar seja algo } \\
\text { pessoal e não seja menos interessante que } \\
\text { o todo. Faço a interligação continuada- }\end{array}$ & $\begin{array}{l}\text { Sim, mas conciliando com os demais espaços. For- } \\
\text { mar um aluno cidadão é não conhecer apenas uma } \\
\text { realidade (do seu lugar) mas sim poder fazer uma } \\
\text { análise dos diversos lugares existentes. }\end{array}$ \\
\hline
\end{tabular}

Fonte: Entrevistas com professores, 2016.

Da primeira questão emerge como os professores fazem para realizar o estudo do lugar. A informação que sobressai é a que diz respeito a tomar o local como ponto de partida e início do estudo considerando o que é conhecido por estar próximo e visível. Há pouca menção à escala de análise, no que diz respeito a pensar teoricamente o que pode levar a deduzir que a abstração ainda está distante do fazer do professor. Mas, a nível da experiência, acredito que exista a ideia de que os lugares não são isolados, pois há referência a comparar com outros lugares, a estudar todos os lugares, a considerar o poder e as relações sociais. Outro aspecto que é interessante referir diz da ausência de observações a respeito de conceitos, o que leva a constatação de que são as ações práticas que orientam os trabalhos. Porém, deve ser ressaltado que o mesmo professor que diz que estuda "o local considerando a escala ade analise- local, regional, nacional mundial," ao ser questionado sobre a possibilidade de formação para a cidadania afirma que "Sim, pois o aluno pode fazer as abstrações e compreendendo que o mundo é globalizado e que tudo interfere em todos os lugares".

Um questionamento feito aos professores diz respeito sobre qual o entendimento que eles têm sobre o trabalho com cidadania na escola. Dos entrevistados que atenderam a demanda posta, de início, pensava-se que os que atuam no Ensino Médio tivessem maior clareza dos que os do Ensino Fundamental, motivados pelas temáticas de estudo na disciplina e pelo fato de trabalharem com jovens que já têm maior entendimento da sua condição de sujeitos com identidade e pertencimento. Se os jovens questionam, os professores precisam dar respostas e, diante disso haveria uma maior consciência a respeito, provocada, mesmo que seja de modo externo, ao pensamento e ao fazer docente. No entanto, ao serem questionados sobre se consideram a cidadania importante na escola, as respostas indicam a precária compreensão de entendimento, pois afirmam que sim, que é importante e informam que se comprova por meio da relevância que é atribuída ao fato de serem realizadas atividades de mutirão, ocasionalmente, no dia da coleta 
do lixo no pátio da escola, por exemplo. Mas, ao serem perguntados se é discutida a questão do motivo de haver tanto lixo exposto a resposta é que não se discute, pois no dia-a-dia é difícil ter estes cuidados, o que mostra que esta é uma atitude tarefeira e excepcional que vai ser realizada com o aparato do marketing.

Ainda falando sobre o lixo, foram questionados se entendem o motivo do esgotamento da água da chuva ser precário nos espaços urbanos e causar sérios problemas quando as precipitações de chuva são acentuadas. Todos reconhecem que o fato (dentre outros motivos) decorre da falta de limpeza urbana, pelas bocas de lobo entupidas, pelas calçadas cheias de entulhos. No entanto, não se realizam discussões sobre o papel de cada um na criação do problema, mesmo sendo notória a identificação de quantidade de lixo nesses lugares, o que seria uma boa motivação para pensar a cidadania. Quando o problema ocorre atinge a todos, de modo indiscriminado afetando a circulação de carros e de pessoas na área urbana e, inclusive com água acumulada tanto nas vias públicas como nos entornos das residências particulares e nos prédios. E, de outra parte, seria uma boa motivação para estudar temas da geografia, das condições climáticas, do tipo de solo, da organização urbana, da distribuição da população, mas essa relação não é feita, o que atesta a fragmentação dos conteúdos trabalhados.

A seguir está indicado no Quadro $N^{\circ} 2$ a incidência de respostas dadas pelos professores consultados sobre a afirmação do entendimento do que é cidadania. Como se constata, estas se resumem a atividades esporádicas e fragmentadas que têm, o mais das vezes, referência à temática ambiental, tão em voga nos noticiários atualmente, mas sempre com a superficialidade que leva ou ao alarmismo ou a insignificância da temática. Por outro lado, há indicativo de ações que se caracterizam por sentimento de solidariedade, ligadas como se constatou com o espírito cristão (auxiliar o próximo e ajudar os mais velhos).

Quadro $N^{\circ} 2$

Atividades para trabalhar a cidadania na escola

\begin{tabular}{|l|c|}
\hline Atividades & Indicação \\
\hline Auxiliar o próximo & 18 \\
\hline Ser solidário & 20 \\
\hline Não passar o sinal vermelho & 20 \\
\hline Pagar impostos que deveria reverter em bens comuns & 18 \\
\hline Dia de limpeza coletiva no espaço da escola & 20 \\
\hline Dia de lavar a escola, as paredes e os muros & 20 \\
\hline Dia de plantar arvore & 20 \\
\hline Preservação do ambiente & 20 \\
\hline Não gastar agua em excesso & 20 \\
\hline Direito ao voto & 20 \\
\hline Dia de recolher o lixo acumulado & 20 \\
\hline Ajudar os mais velhos & 17 \\
\hline Responsabilidade & 15 \\
\hline
\end{tabular}

Fonte: Entrevistas com professores, 2016. 
De um modo geral, pode-se constatar que a indicação em si desses itens não são um problema. Mas sim é problemático a indicação da falta de contextualizar estas questões, que são problemas que os homens criam e que se avolumam de modo que uma ação se torna excepcional a ponto de merecer o destaque midiático. A aula é substituída pela atividade que é uma tarefa a ser cumprida e, muitas vezes, no contexto de uma gincana em que os grupos se organizam como concorrentes em busca de uma premiação e com os meios de comunicação envolvidos na divulgação. Passada a "festa" tudo volta ao normal.

Neste universo (pesquisado) de professores que atuam na escola básica ensinando geografia, $33 " \%$ deles são formados em História e os demais em Geografia, e isto pode descaracterizar a ação do professor que leciona geografia seja pela formação diferenciada, seja pelas formas de atuação na sala de aula com um conteúdo disciplinar que não dominam. Estes professores que fizeram o outro curso têm as bases teóricas da sua especificidade e mesmo havendo muita proximidade entre história e geografia há diferenças que são epistemológicas. As discussões teóricas e os conceitos fundamentais de cada disciplina não são os mesmos. Estão destacadas a seguir as respostas dadas pelos professores ao serem questionados sobre a definição de cidadania com a pergunta "Como professor qual tua ideia sobre a formação cidadã?" (Quadro № 3).

\section{Quadro $N^{\circ} 3$}

Como professor qual tua ideia sobre a formação cidadã?"

- O problema da formação cidadã na sociedade brasileira é puramente "a falta de conteúdo", temos uma cultura rica que não é valorizada. Falta uma educação voltada para a cultura, a filosofia, que nos leve a pensar no "eu", mas também no coletivo. Isso é cidadania.

- Falta muito a ser trabalhado ainda. Já foi mais fácil trabalhar com a ideia de comprometer-se com a sociedade em que se vive. Eles vivem mais no imediatismo e, muitas vezes, têm ideia errada do poder que têm de interferir nas decisões políticas no lugar onde moram. Atrelada a própria acomodação de que nunca vá mudar, sempre foi assim.

- Considero difícil atribuir essa ideia (formação cidadã) somente à escola, é preciso que a sociedade toda participe, como a família, e o Estado.

Fonte: Entrevistas com professores, 2016.

Constata-se nesses depoimentos o entendimento que beira a descrença da possibilidade de formação cidadã na escola. Os professores expressam a dificuldade quando se atribui a responsabilidade apenas para a escola. Mas indicam também a dimensão da contextualização na sociedade em que se vive nesses tempos, de egoísmos, individualismos e ausência de pensar nos grupos como e com solidariedade.

Noutro grupo há posicionamentos que mostram o entendimento da questão e a importância de ser trabalhada na escola a formação para a cidadania. Mas a ideia é ainda na perspectiva da idealização, pois carece de ligação com os conteúdos e com o papel da escola na condução do acesso ao conhecimento pelos alunos. $\mathrm{E}$, do mesmo modo, não há referência aos conceitos que permitam abordar os conteúdos de modo a encaminhar pra a formação cidadã. E os indícios aqui apresentados podem ter um significado da intenção, o que pode ser uma brecha para se trabalhar 
na formação continuada dos professores. Mas essa só terá efetividade se acontecer por meio do trabalho de discussão e de reflexão da própria prática, pois essas observações que os professores fazem compõem um interessante rol de temas que podem motivar a própria formação continuada.

Novamente os indícios apontam possibilidades, pois diante de um questionamento sobre se o entrevistado considera que o professor da escola básica tem consciência de ser cidadão, as respostas variam: "-Alguns tem sim; nem todos; todo professor deveria ter, mas...; alguns sabem o que é ser cidadão, mas não agem com tal, falta ética; em alguns momentos sim, noutros não; deveria ter, mas nem sempre tem". Também são enfáticas as respostas que dizem que ao exercer a profissão com dignidade e responsabilidade o professor está mostrando com exemplos a sua cidadania. Essas ideias apontam a possibilidade de trabalho de formação continuada (já referido) tendo como parâmetro as questões teóricas que encaminham a formulação de conceitos e para sua instrumentação o trabalho com os conteúdos (Quadro N 4).

\section{Quadro $N^{\circ} 4$}

"o entrevistado considera que o professor da escola básica tem consciência de ser cidadão"

- É essencial. O nosso foco é formar alunos cidadãos. Alunos que participam, que interagem, que estejam motivados e preocupados com o futuro, que possam fazer a diferença na sociedade.

- É aprender a ser cidadão, aprender a agir com respeito, solidariedade e responsabilidade. Esses valores e atitudes precisam ser aprendidos e desenvolvidos pelos estudantes e, portanto, podem e devem ser ensinados na escola.

- Para mim a formação cidadã é o comprometimento e a responsabilidade que o ser humano deve ter com a vida, com a sociedade, com a cultura, com a política, com a economia, com o meio ambiente, tudo isso alicerçado em valores e virtudes essenciais como: solidariedade, respeito, ética, honestidade, coerência, justiça, gratidão..."

- Ser cidadão é poder opinar e transformar, naquele momento que você acha que não está correto. Poder eleger os seus representantes. Ajudar os alunos a entender que eles são parte desse processo de mudança, de preferência para melhor.

- Eles devem ser agentes que transformarão o meio em que vivem e com isso também transformar a sua vida e a sociedade de uma maneira que beneficia a todos. É quando uma pessoa sabe que tem obrigações a cumprir e exigir seus direitos. Mas em primeiro lugar cumprir suas obrigações. As pessoas hoje pensam somente nos direitos.

- A formação cidadã é muito importante, não apenas nas Ciências Humanas, devendo permear todo o currículo e atividades da escola. Deve ser construída desde a primeira infância dentro de casa, pois o primeiro exemplo é da família.

- Seria importante para mudar a consciência política dos alunos para construir uma sociedade melhor, sem corrupção.

- A criança ou adolescente seja um ser ativo na comunidade, participando de ações concretas que beneficiam de alguma maneira as pessoas mais necessitadas, independentemente da necessidade. Que eles possam se reconhecer como pessoas da comunidade com respeito e honestidade. 
Essas posições consideram a possibilidade de fazer na escola essa formação cidadã, de um modo bem pragmático. Destacam a formação com valores, com solidariedade e com responsabilidade e participação. $\mathrm{E}$, merece ser destacado, dentre os conceitos formulados pelos entrevistados, o de uma professora de geografia, por abordar o assunto de uma maneira diferente dos demais, ressaltando a importância de se conhecer o local onde vive e situar-se dentro dele para que ocorra concretamente a cidadania. A disciplina de geografia ganha importante espaço no currículo desde as séries iniciais, pelos assuntos de que trata, visto que o aluno está num processo de constituição de sua identidade e pertencimento. Mais do que ler e escrever, é importante que o aluno saiba ler e interpretar o mundo. A geografia tem o papel de situar o aluno como parte integrante de uma sociedade, de uma história e de um espaço construído pela vida dos homens.

\section{O livro didático e a cidadania}

É importante abordar a questão do livro didático pois este é o maior instrumento de apoio para o desenvolvimento da aula na disciplina de geografia. (Callai: 2014; Callai \& Castellar, 2015; Callai \& Deon, 2016). Nas entrevistas realizadas com os professores a indicação de uso do livro é majoritária, inclusive há o depoimento de professores que dizem que devido as condições de trabalho e a quantidade de turmas que deve atender por semana a única possibilidade de realizar o trabalho é seguindo o livro didático como orientador/definidor das atividades e da condução do trabalho em sala de aula, com exclusividade. No Quadro $N^{\circ} 5$ está apresentado o número de docentes que atendem a indicação feita a respeito do uso do livro.

\section{Quadro $N^{\circ} 5$}

Uso do livro didático pelo professor de geografia na escola básica

\begin{tabular}{|l|r|}
\hline Os professores dizem: & Indicação \\
\hline - Uso sempre. É a minha orientação única; & 18 \\
\hline - Uso porque a escola adota; & 15 \\
\hline - Uso, mas não apenas o livro; & 5 \\
\hline - Uso porque estão melhores agora; & 20 \\
\hline - Uso como apoio pedagógico; & 10 \\
\hline - Uso como um recurso didático. & 13 \\
\hline - Uso vários para aproveitar o que tem de mais adequado em cada um; & 4 \\
\hline - Uso, mas não sigo o roteiro; & 2 \\
\hline - Não uso em função da inúmeras contradições de um autor para outro, & 1 \\
\hline & inclusive com alguns erros; \\
\hline
\end{tabular}

Fonte: Entrevistas com professores, 2016.

Nessa questão é importante assinalar os caminhos que o livro didático percorre no Brasil, até estar na sala de aula e nas mãos do professor, que é um longo processo de elaboração e avaliação denominado PNLD - Programa Nacional do Livro Didático. No contexto desse programa, nas orientações para a avaliação dos LD um dos itens abordados (que é do nosso interesse neste texto) diz respeito a "Construção da Cidadania e Convívio Social Republicano" cuja orientação indica um rol de cuidados a serem seguidos na análise. 
"Está isenta de estereótipos e preconceitos relativos à origem, condição socioeconômica, regional, étnico-racial, de gênero, religião, de orientação sexual, de idade ou de linguagem, assim como qualquer outra forma de discriminação ou de violação de direitos? Está isenta de doutrinação religiosa, política e/ou ideológica, que desrespeite o caráter laico e autônomo do ensino público? Promove positivamente a imagem da mulher, considerando sua participação profissional e em espaços de poder, através do texto escrito, das ilustrações e das atividades dos livros didáticos, reforçando sua visibilidade? Aborda a temática de gênero e da não violência visando à construção de uma sociedade não sexista, justa e igualitária, inclusive no que diz respeito ao combate à homofobia? Contribui para a educação no âmbito das relações étnico-raciais e indígenas promovendo, por meio da inserção de ilustrações, textos e demais elementos, a imagem de afrodescendentes e descendentes de etnias indígenas brasileiras, considerando sua participação profissional e em espaços de poder e dando visibilidade aos seus valores, tradições, organizações e saberes na formação do espaço geográfico brasileiro?" (Brasil, 2014: 20-21).

Diante dessa citação, com os indicadores de respeito e promoção à cidadania, se pode verificar o cuidado com a questão que a geografia tem para trabalhar as temáticas de cidadania. O que se constata é que essas orientações não são em hipótese alguma desrespeitadas nos livros. Pelo contrário, elas são cuidadosamente cumpridas, no entanto, não vão muito além da sua apresentação, pois não há aprofundamento e nem desdobramentos para que seja construída uma consciência cidadã. Aliás, na sociedade brasileira de um modo geral essas questões, antes referidas na citação, têm tido progressos com a discussão aberta publicamente a partir das políticas afirmativas. No entanto, não é tranquila no sentido de aceitação e reconhecimento e, em artigo que trata do invisível, ocultos e silenciados (Callai \& Deon, 2016) esse tema é analisado, e se observa muitas figuras, por exemplo, que indicam as questões, tornando-as presentes, no entanto, sem maiores avanços na discussão, sem proposição de aprofundamento. Questiona-se, portanto, se apenas pelo fato de mostrar a figura já está cumprida a tarefa de contribuir para a compreensão da questão, o que é discutível.

Ao considerar o livro didático para verificar a contribuição dos mesmos na formação para cidadania os questionamentos feitos aos professores se referia a ver se eles têm no livro didático um auxiliar capaz de contribuir para a formação cidadã e as respostas podem ser sistematizadas em dois blocos, a seguir destacados. As afirmações apresentadas, podem ser unificadas com os indícios de que não há contribuição significativa, pois existe a abordagem dos temas, as questões aparecem nos livros, no entanto, o que é feito com o material não é significativo para a formação cidadã (Quadro № 6).

\section{Quadro $N^{\circ} 6$}

"os professores têm no livro didático um auxiliar capaz de contribuir para a formação cidadã"

1- Sim, os livros didáticos apresentam textos que dizem que ser cidadão é importante; mostram figuras que indicam que a cidadania e que ser cidadão é importante; há sugestões de atividades para estudar a cidadania.

2- Sobre o que fazem com essas indicações as respostas dos professores dizem que mandam os alunos ler os textos, fazer os resumos, responder as questões apresentadas. Isso sempre em horário fora da sala de aula, pois no limite da aula não há tempo para fazer essas atividades. E o conteúdo deve ser cumprido, portanto não há espaço para maiores discussões. 
Como forma de contraponto e inclusive como motivação para a compreensão dessas respostas é interessante revisitar os resultados de uma pesquisa realizada em Sevilha - Espanha e ljuí-RS-Brasil (Callai \& García Pérez, 2016: 23-42). Com os dados produzidos a partir dos professores em formação foi estabelecido um sistema de categorias que permitiram analisar o que estes sujeitos expressam a respeito da cidadania. As categorias básicas definidas foram: 1. Concepção de cidadania e, portanto, de educação para a cidadania; 2. Papel e significado da participação cidadã como conteúdo educativo (que permite ter a ideia de participação cidadã que integre conceitos, procedimentos, atitudes e valores e a ação cívica); 3. maneira de trabalhar a participação cidadã (no sentido de fazer a reflexão sobre problemas sociais relevantes); 4. Integração de planejamentos educativos "não escolares" no currículo (superação da tradição disciplinar exclusivamente e incorporação de proposições educativas mais amplas, abertas a interdisciplinaridade); 5. Compromisso com os problemas sociais e sua resolução como parte integrante da identidade profissional docente (comprometimento com os problemas sociais). O descortinamento dessas concepções presentes na organização curricular e principalmente no modo de entendimento dos futuros professores acentua a percepção do que acontece nas escolas a partir dos depoimentos dos professores que atuam no ensino básico. Essas constatações encaminham a formar uma ideia a respeito do que se entende por educação e formação cidadã, no contexto do mudo atual para além das singularidades de países e povos.

\section{Como compreender o papel da geografia na formação cidadã}

Tendo como referência as intenções da realização dessa reflexão, aliada à contribuição de dados empíricos, na busca de construção de uma educação geográfica, tendo a perspectiva da formação e educação para a cidadania, alguns resultados podem ser vislumbrados e que podem servir para pensar a geografia escolar na escola básica. Neste sentido, retomando aquilo que são os pontos básicos de intenção desse texto, as considerações finais podem ser um fechamento, mas ao mesmo tempo a abertura para novos estudos e novos entendimentos. Isso requer que se considere as perspectivas teóricas que fundam a pesquisa na área das humanidades, os pressupostos teóricos e metodológicos que possibilitam o avanço do entendimento das questões da vida, que é, em última análise, o motivo essencial que nos move. E, do mesmo modo, interessa a produção empírica que se constitui no elo capaz de contribuir na elaboração de ideias para pensar a escola, os professores e o ensino que, no caso, é o da geografia.

Como principais resultados possíveis de serem apresentados, constata-se que a educação geográfica é entendida como a possibilidade de compreender que o espaço que nos abriga e nos acolhe, que é construído por nós e ao mesmo tempo em que fazemos a história acontecer, vamos deixando rastros que materializam o que resulta dos processos vividos. $E$, nesse bojo está a busca pela construção da cidadania, que é constitutiva da educação geográfica. Mas, ao mesmo tempo que se constata este entendimento pela bibliografia estudada, pelos depoimentos dos professores, nos enunciados dos livros didáticos e pelo uso que o professor faz dos mesmos, enfim, nas suas ações práticas como docente da escola, isso está longe de acontecer, seja pela organização espaço-temporal da escola e do ensino, seja pelo papel do livro didático que tem sido utilizado como o único instrumento para a realização do ensino e, assim, a aprendizagem do aluno se restringe a mera repetição de conteúdo. 
O direito de ser cidadão numa sociedade republicana é inalienável e faz parte das prerrogativas dos sujeitos, mas que, no entanto, vivem as suas vidas das formas mais diferenciadas que possam existir, causada pela desigualdade no acesso aos bens produzidos. Fazer uma educação para a formação cidadã requer o reconhecimento de que todos têm direitos e também deveres, mas além de muitos não terem os mínimos direitos de sujeitos cidadãos, existem desigualdades muito grandes na sociedade brasileira. $E$, essas desigualdades, não se restringem a questões étnicas de gênero etc., (também significativas), mas sim e principalmente de acesso aos bens produzidos pelos homens. A desigualdade é social e é econômica e, nesse sentido, para determinados grupos elas se acentuam ainda mais. Fazer uma educação para a formação cidadã significa então mais do que reconhecer problemas sociais, ambientais, econômicos, significa fazer o exercício da crítica e compreender o significado desses problemas. Essa crítica exige a observação, a interpretação e a compreensão dos problemas, mas não apenas para enunciá-los e sim para encontrar soluções, caminhos que possam contribuir para que a escola seja de fato um lugar de aprendizagem a que todos têm direito. Assim, pode-se entender que o acesso ao conhecimento é um dos motores para desencadear atitudes cidadãs. E a escola é o lugar do conhecimento, um conhecimento que pode dar poder a quem não o tem.

Por outro lado, no mundo atual, à medida que a globalização nos passa a impressão de que as diferenças entre pessoas (econômicas, culturais, sociais) vão sendo amenizadas, mas que na verdade estas vão sendo cada vez mais aprofundadas, cresce a necessidade de que haja cidadãos atuantes no meio em que vivem. (Santos, 2000). A construção da cidadania depende do sentimento de pertencimento ao lugar em que se vive, que a pessoa se reconheça como sujeito integrante de uma realidade, sendo parte de uma história e de um espaço construído pela vida dos homens, como fator indispensável para a comunidade, e não como simplesmente mais um integrante no mundo. Antes de ser cidadão do mundo, é necessário ser cidadão no local onde se vive (Callai \& Zeni, 2011) e, considerando que não são apenas regras e normas a serem cumpridas que permitam desenvolver a formação para a cidadania, é que centramos na ideia de que por meio do acesso ao conhecimento se pode construir a vida solidária.

Cabe ainda salientar a questão da escala de análise que se constitui numa ferramenta intelectual que configura a orientação de como fazer a análise geográfica e desenvolver o pensamento espacial para entender o mundo e a identidade e o pertencimento dos sujeitos. Um sujeito sem identidade não tem como se constituir e se compreender como um cidadão. A formação cidadã se constitui no elo que dá significado ao ensino da geografia, no sentido de que o aluno compreenda o mundo da vida e seja capaz de produzir o conhecimento como sujeito que tem identidade e pertencimento ao mundo que é global.

E, diante dessa caracterização do espaço, é que se torna importante para a geografia escolar, no sentido de entender o mundo em que vivemos, superar a fragmentação dos conteúdos tornando-os organizados para que façam sentido e tenham significado na aprendizagem. Esses conteúdos são o conhecimento produzido pela humanidade e que à escola cabe ensinar de um modo organizado, fazendo a sistematização e tendo os conceitos como elementos fundamentais. Para tanto, torna-se adequado considerar as escalas de análise na interpretação daquilo que vivemos e observamos. O local e global e as dimensões de espaço absoluto, relativo e relacional devem ser considerados e abordados sempre na perspectiva dialética. 
Assim, estudar o lugar com essa perspectiva nos anima a estabelecer os caminhos para compreender o mundo. As relações entre os homens se sustentam em interesses geopolíticos e compreender os significados destes exige avançar além da simples observação e constatação. A análise e a interpretação são fundamentais. Este olhar permitiria avançar no ensino da geografia tornando-a uma educação geográfica em que o pensamento espacial contribua para compreender a vida. E ser cidadão decorre disso. Os resultados empíricos permitem a caracterização do problema na escola, e com o olhar teórico podem ser produzidas alternativas para o ensino de uma geografia cidadã, para a formação de professores com esta perspectiva e, no limite que interessa, para fazer uma educação para a formação cidadã por meio da educação geográfica.

\section{Referências Bibliográficas}

BORGHI, B.; GARCíA PÉREZ, F.F. \& MORENO FERNÁNDEZ, O. Noví Cíves - Cittadini dall'infanzia in poi. Bologna: Pàtron Editore, 2015.

BRASIL. Departamento de Educação do Distrito Federal. Programa de ciências sociais, Vol.2, $4^{\circ} \mathrm{e}$ $5^{\circ}$ anos. São Paulo: Cia. Editora Nacional, 1934.

BRASIL. Presidência da República. Lei 9.394, 20 dezembro 1996. Diretrizes e Bases da Educação Nacional. Brasília: (1996). Disponível em Internet:

www.planalto.gov.br/ccivil_03/leis/L9394.htm

BRASIL. Ministério da Educação Parâmetros Curriculares nacionais: história e geografia. Brasília: Ministério da Educação, Secretaria de Educação Fundamental,1997. Disponível em Internet: http:// portal.mec.gov.br/seb/arquivos/pdf/geografia.pdf

BRASIL. Ministério da Educação. Orientações curriculares para o ensino médio, Ciências Humanas e suas tecnologias. Brasília: Ministério da Educação, Secretaria de Educação Básica, 2006. Disponível em Internet:

http://portal.mec.gov.br/seb/arquivos/pdf/book_volume_03_internet.pdf

BRASIL. MINISTÉRIO DA EDUCAÇÃO. Diretrizes Curriculares Nacionais da Educação Básica. Brasília: Ministério da Educação, Secretaria de Educação Básica, 2013. Disponível em Internet: http://portal.mec.gov.br/docman/julho-2013-pdf/13677-diretrizes-edcacao-basica-2013-pdf/file

BRASIL. MINISTÉRIO DA EDUCAÇÃO. Guia de livros didáticos PNLD 2015: geografia, ensino médio. Brasília: Ministério da Educação, Secretaria de Educação Básica, 2014. Disponível em Internet: http://www.fnde.gov.br/programas/programas-do-livro-/livro-didatico/guia-dolivrodidatico/ item/4661-guia-pnld-2014

BRASIL. Constituição. República Federativa do Brasil. Brasília: Supremo Tribunal Federal, Secretaria de Documentação, 2017. Disponivel em Internet: http://www.stf.jus/br/arquivo/CMS/legislacaoConstituicao/anexo/CF.pdf

CALLAI, H.C. Escola, cotidiano e lugar. In: BUITONI, M.M.S. (coordinador). Geografía, ensino fundamental. Brasilia: Ministério da Educação, Secretaria de Educação Básica, 2010, p. 25-41. 
CALLAI, H.C. \& ZENI, B. Sch. A importância do lugar: construindo cidadania na fábula perversa do globalitarismo de Milton Santos. Teoria \& Sociedade, 2011, Vol. 19, № 1, p.62-75.

CALLAI, H.C. Estudar a paisagem para aprender geografía. In: GARRIDO PEREIRA, M. (compilador). La opacidad del paisaje: formas, imágenes y tiempos educativos. Porto Alegre: Editora Imprensa Livre, 2013, p. 37-56.

CALLAI, H.C. Estudo do lugar e o livro didático no ensino e na aprendizagem da Geografia. In: FERNANDEZ CASO, M.V. \& GUREVICH, R. (Dir.). Didáctica de la Geografía: prácticas escolares y formación de profesores. Buenos Aires: Biblos, 2014, p. 61-73.

CALLAI, H.C. \& CASTELLAR, S.M.V. La geografía en la construcción de la ciudadanía: lo visible y lo invisible en el libro didáctico. In: $28^{\circ}$ Simposio Internacional de Didáctica de las Ciencias Sociales, Cáceres, 2015. Vol. 1, p. 687-693.

CALLAI, H.C. \& GARCÍA PÉREZ, F.F. A Educação para a cidadania e a pesquisa. In: CALLAI, H.C. \& MORAES, M.M. Pesquisa, Educação e cidadania- percursos teóricos e metodológicos. ljuí: Editora Unijuí. 2016, p.23-42.

CALLAI, H.C. \& DEON, A.R. Desafios do Ensino de Geografia: A cidadania como possibilidade de discussão no livro didático do Ensino Médio. 2016. [Inédito].

GARRIDO PEREIRA, M. (editor). La espesura del lugar: reflexiones sobre el espacio em el mundo educativo. Santiago de Chile: Universidad Academia de Humanismo Cristiano, 2009.

HAESBAERT, R. Territórios alternativos. Niterói: Editora UFF, Editora Contexto, 2002.

HARVEY, D. La geografia como oportunidade de política de resistencia y construcción de alternativas. Espacios Revista de Geografia, 2012, Vol. 2, № 4, p. 11-28.

LASTORIA, A.C.; CALLAI, H.C.; CAVALCANTI, L. \& SOUZA, V.C. School education in Brazil and the goal of citizen formation; indicators in oficial proposals and in formative practices. In: BORGHI, B.; GARCÍA PÉREZ, F.F. \& MORENO FERNÁNDEZ, O. Noví Cíves - Cittadini dall infanzia in poi. Bologna: Pàtron Editore, 2015, p. 43-52.

LASTORIA, A.C.; CALLAI, H.C; CAVALCANTI, L. \& SOUZA, V.C. Cittadinanza ed educazione per la cittadinanza nel contesto brasiliano. In: BORGHI, B.; GARCÍA PÉREZ, F.F. \& MORENO FERNÁNDEZ, O. Noví Cíves - Cittadini dall infanzia in poi. Bologna: Pàtron Editore, 2015, p. 191-199.

MASSEY, D. Pelo espaço, uma nova política e espacialidade. Rio de Janeiro: Bertrand Brasil, 2008.

PINSKY, J. Cidadania e educação. São Paulo: Editora Contexto, 1999.

SANTOS, M. Metamorfoses do espaço habitado. São Paulo: HUCITEC, 1988.

SANTOS, M. Técnica, espaço, tempo: globalização e o meio técnico-científico informacional. São Paulo: HUCITEC, 1994. 
SANTOS, M. A natureza do espaço, técnica e tempo, emoção e razão. São Paulo: HUCITEC, 1996.

SANTOS, M. Por uma outra globalização, do pensamento único à consciência universal. Rio de Janeiro: Editora Record, 2000.

YOUNG, M. O futuro da educação em uma sociedade do conhecimento: o argumento radical em defesa de um currículo centrado em disciplinas. Revista Brasileira de Educação, 2011, Vol. 16, № 48, p. 609-623. 